\title{
Clinical and penile Doppler outcomes using a modified, tourniquet free, Nesbit plication for severe Peyronie's disease
}

\author{
Vincenzo Maria Altieri ${ }^{1}$, Francesco Greco ${ }^{2}$, Rocca Carmela Lisanti ${ }^{2}$, Barbara Altieri ${ }^{3}$, Francesco Esperto ${ }^{4}$, \\ Luca Cindolo ${ }^{5}$, Roberto Castellucci ${ }^{6}$, Pier Andrea Della Camera ${ }^{7}$, Giuseppe Massimo Sangiorgi ${ }^{8}$, Vittore \\ Verratti $^{9}$
}

${ }^{1}$ Department of Urology, Policlinico di Monza, Monza; ${ }^{2}$ Urologic Clinic, Centro Salute Uomo, Bergamo, Italy; ${ }^{3}$ Division of Endocrinology and Diabetes, Department of Internal Medicine I, University Hospital, University of Würzburg, Würzburg, Germany; ${ }^{4}$ Department of Urology, Campus Biomedico, University of Rome, Rome, Italy; ${ }^{5}$ Department of Urology, "Villa Stuart" Private Hospital, Rome, Italy; ${ }^{6}$ Department of Urology, SS. Annunziata Hospital, ASL 2 Abruzzo Chieti, Italy; ${ }^{7}$ Department of Urology, University of Florence, Careggi University Hospital, Florence, Italy; ${ }^{8}$ Department of Biomedicine and Prevention, University of Rome Tor Vergata, Rome, Italy; ${ }^{9}$ Department of Psychological, Health and Territorial Sciences, University “G. d'Annunzio" Chieti-Pescara, Chieti, Italy

Contributions: (I) Conception and design: VM Altieri, F Greco, V Verratti; (II) Administrative support: VM Altieri, F Greco, V Verratti; (III) Provision of study materials or patients: VM Altieri, F Greco, RC Lisanti, F Esperto, L Cindolo, R Castellucci, PA Della Camera, GM Sangiorgi; (IV) Collection and assembly of data: VM Altieri, F Greco, B Altieri, L Cindolo, V Verratti; (V) Data analysis and interpretation: All authors; (VI) Manuscript writing: All authors; (VII) Final approval of manuscript: All authors.

Correspondence to: Vittore Verratti, MD, PhD. Department of Psychological, Health and Territorial Sciences, University "G. d'Annunzio" of ChietiPescara, via dei Vestini 31, 66100 Chieti, Italy. Email: vittore.verratti@unich.it.

Background: Penile curvature (PC) can be surgically corrected by plication techniques or Nesbit corporoplasty. These shortening techniques can be complicated by post-operative: penile shortening, recurrent PC, palpable suture knots and erectile dysfunction. Furthermore, Nesbit procedures require the use of a penile tourniquet to avoid intraoperative bleeding. This observational study aims to assess the results of Nesbit modified corporoplasty, avoiding intraoperative use of tourniquet without risk of bleeding. The objective is to reduce penile ischemic anatomical and functional damages such as long-term erectile dysfunction.

Methods: Between January 2010 and March 2019, a total of 64 patients with congenital penile curvature (CPC) and Peyronie's disease (PD) underwent surgical correction with a Nesbit modified technique first time described by Rolle et al., with minimal technical differences. The operation notes were retrospectively reviewed. In particular, we evaluated pre- and post-operative erectile functions using IIEF-5 score, penile Doppler ultrasonography and overall patient satisfaction.

Results: During operations, no intraoperative bleeding was noted, and no short-term complications such as hematomas or neurovascular bundle lesions were reported. At 6 months, no palpable subcutaneous indurations and no sensory change were detected. Post-operative penile shortening was reported in 38 $(59.4 \%$ ) patients (mean $0.83 \pm 0.79 \mathrm{~cm}$ ), but it did not influence the high overall satisfaction rate of $91.4 \%$. Only 2 patients reported a slightly partial recurrence of curvature $(<15 \%)$ with no need for a redo surgery. Mean IIEF-5 score increased from $17.1 \pm 5.2$ to $20.8 \pm 3.9$ at 6 months and $21.8 \pm 3.4$ at 12 months $(\mathrm{P}<0.001$ in both cases). Mean PSV also significantly increased at the end of follow-up (28.5 \pm 6.1 at baseline vs. $31.0 \pm 7.1$ at 12 months, $\mathrm{P}=0.03)$.

Conclusions: Considering the optimal results in terms of erectile functions increasing and absence of PC recurrence $\left(>15^{\circ}\right)$, we think that Nesbit modified corporoplasty without tourniquet application during reconstruction is a safe and effective surgical procedure for all kind of shortening corporoplasty to reduce the time of penile ischemia, preventing even serious consequences for the normal physiology of erection.

Keywords: Modified Nesbit corporoplasty; congenital penile curvature (CPC); Peyronie's disease (PD); hypoxicischemic damages 
Submitted Oct 13, 2020. Accepted for publication May 10, 2021.

doi: $10.21037 /$ tau-20-1338

View this article at: https://dx.doi.org/10.21037/tau-20-1338

\section{Introduction}

Congenital penile curvature (CPC) is a rare condition with an incidence of less than $1 \%$ (1). Instead, Peyronie's disease (PD) is relatively common and affects up to $20.3 \%$ of adult men to some degree (2) whose conservative treatment is usually successful during the active phase (3). If the curve in the penis continues during the stable phase and plaques are completely stabilized, surgery is generally the best treatment, mainly if there are problems with having sexual intercourse (4). Orally treatments with vitamin $\mathrm{E}$, potassium para-aminobenzoate and tamoxifen have been used in the initial phase with low success rates (5). Penile shortening procedures are used when the curvature is less severe and include the Nesbit wedge resection and the plication techniques performed on the convex unaffected side of the penis. Penile lengthening procedures are performed on the concave side of the penis and require the use of a graft (6-9). Moreover, lengthening runs a greater risk of erectile dysfunction. The geometrical technique is the most used procedure for recovering the length lost by scarring (10). Different types of tourniquets have been used during these procedures to avoid intraoperative bleeding and to reduce operating time $(6,11-13)$. The safe time for the application of a tourniquet in penile surgery has not been established, but Bozkurt et al. (14) investigated the effects in rabbits of short and long times on corporal nerves, endothelium and smooth muscle responses, as the innervation of rabbit corpus cavernosum is similar to human corporal tissue (15). They demonstrated that, during the 40 and 60 min tourniquet application and 5 min reperfusion time, the increase of free oxygen radicals might alter the levels of nitric oxide that reach the smooth muscle. According to the results of their study, an application time of up to $20 \mathrm{~min}$ is more appropriate. Another study confirmed that prolonged penile tourniquet application might result in altered growth factors and acute inflammation of penile tissue. This event may then cause poor angiogenesis in penile skin flaps until reduced the success rate of repair (16). An interesting hypothesis is that, from a physiological and pathophysiological point of view, the reduction of the ischemic time guarantees less hypoxic/ ischemic damage. In this regard, hypoxic suffering, in addition to the more well-known effects on the regulation of ventilation mediated by the carotid glomus (17) and cardiac activity (18), involves significant physiopathological effects on the mechanism of erection (19), as demonstrated in some of our previous works $(20,21)$. Moreover, it has been shown that a hypoxic/ischemic injury, for example from an entrapped pool of blood during veno-occlusive ischemic priapism (22), might facilitate (if not induce) tissue hypoxia. This results in erectile tissue fibrosis of the penis, reducing the structural elasticity, which then leads to alteration (sometimes permanent) of the pro-erectile physiological mechanism (23).

Considering what has been discussed, the aim of this study was to confirm the efficacy of Nesbit corporoplasty, modified by Rolle and colleagues (24), as a useful surgical technique with the rationale to reducing the time of penile ischemia and for increasing the post-operative erectile functions in patients with CPC or PD with normal spontaneous erection or erectile dysfunctions that respond to the medication. We present the following article in accordance with the STROBE reporting checklist (available at http://dx.doi.org/10.21037/tau-20-1338).

\section{Methods}

\section{Study design}

We performed an observational study including 64 patients with CPC or PD who had a normal spontaneous erection or erectile dysfunction that responds to oral therapy with type5 phosphodiesterase inhibitors, and who underwent surgical correction with Rolle et al. Nesbit modified corporoplasty technique (24) between January 2010 and March 2019. Initially the study should have included a time span of 10 years [2010-2020]. However, the serious consequences of coronavirus disease (COVID-19) that exploded in March 2020 forced the recruitment deadline to March 2019, since patients admitted to the study after March 2019 could not complete the 12-month follow-up. Patients were operated from a one single surgeon with the same surgical standards. Patients who do not respond to medication were treated 
with prosthesis implantation and were excluded from the study group. Another exclusion criterion was the presence of complex penile curvatures (PC) with an angle of $90^{\circ}$ in patients, and that took advantage of lengthening procedures with plaque incision and grafting with bovine pericardial to cover the albugineal defect. Patients with a follow-up shorter than 12 months were also excluded from the study.

The preoperative evaluation consisted of detailed medical history and physical examination, including the evaluation of PC, penile doppler ultrasound and sexual activity. Measurement of PC was done by taking photographs in three positions after a drug-induced erection (by injecting of prostaglandin). Erect penile length was also measured during artificial erection. Penile Doppler ultrasound was performed after drug-induced erection to check the size of the plaque and to evaluate hemodynamic function by the evaluation of a peak systolic velocity (PSV). Severity of PDV was evaluated as: $>35 \mathrm{~cm} / \mathrm{s}$ normal, $25-35$ gray zone, $<25$ abnormal (25). Erectile function was assessed by the simplified International Index of Erectile Function (IIEF-5) and categorized as no-ED (score 22-25), mild ED (score 17-21), mild-to-moderate ED (score 12-16) and moderate or severe ED (score 1-11) (26). Clinical characteristics were correlated with the presence of ED or abnormal PVS at baseline.

The surgery procedure performed in all patients was the same modified Nesbit technique. All patients were postoperatively evaluated for one year. A weekly shortterm post-operative evaluation was done until the complete wound healing and to rule out early complications. After a period of 6 months, tardive complication and sexual activity were evaluated by IIEF-5. After 1 year of followup, a complete physical examination, with evaluation of the achievement of complete straightness, residual curvature $\left(>15^{\circ}\right)$, penile shortening and palpable suture knot was performed. Moreover, penile Doppler ultrasonography, erectile function by IIEF-5 and patient satisfaction were also evaluated at this time-point. To determine patient satisfaction rate, we used five questions, which require the respondent to select their level of satisfaction, from "very dissatisfied" to "very satisfied" (27). Clinical outcome was evaluated by the change in ED and PVS along with the severity at the baseline and the end of the study.

The study was conducted in accordance with the Declaration of Helsinki (revised in 2013) and was approved by the Ethics Committee for Biomedical Research of the provinces of Chieti and Pescara and the 'G. D'Annunzio' University of Chieti and Pescara (01/26-01-2017). A written informed consent was obtained from all patients.

\section{Operative techniques}

All patients had surgery under spinal anesthesia. A circumferential subcoronal incision was made, and the penile skin degloved. After a constricting of the penile root was induced an artificial erection with intracorporeal injection of saltwater solution, to confirm the curvature and to measure the angle (Figure 1A,B). Buck's fascia was periurethral incised and bilateral neurovascular bundles dissected from the worksite, after removing tourniquet. Plication procedures of the tunica albuginea were made opposite the point of maximal curvature, and another check was made with a new induced artificial erection. Under the Allis forceps, we made a horizontal mattress continuous suture using a 2-0 absorbable polyglactin 910 through the full thickness of the tunica albuginea to approach the flaps (Figure $2 A, B, C$ ). Then we removed the forceps, and we remove the albugineal excess tissue with a scalpel (Figure $3 A, B, C, D)$. To ensure the albugineal breach, we used an over and over interrupted suture with 2-0 absorbable polyglactin 910 (Figure $4 A$ ). During this procedure, the absence of bleeding did not require penis closure with a tourniquet (Figure $4 B$ ). The same operative steps were performed in the other point of "corpora cavernosa" until curvature was corrected. After that, a full erection was induced by injection of saline solution to check that the curvature had been completely corrected (Figure 5A). Finally, Buck's fascia was closed (Figure 5B), and circumcision was made in all the cases (Figure 6A,B). In all patients, the urethral catheter was placed for one day, and they were discharged 2 days after having the surgery. At one-month, follow-up patient's photos during spontaneous erection were taken and attached to their electronic medical record (Figure 6C,D).

\section{Statistical analysis}

Continuous values were reported as median and range or as mean \pm standard deviation (SD) when showed as differences between groups. The Chi-square $\left(\chi^{2}\right)$ test was used to compare categorical variables, while a two-sided $t$-test (or non-parametric equivalent) was used to compare continuous variables. Odds Ratio (OR) were calculated with $95 \%$ confidence intervals (95\% CI). A non-parametric Friedman test for repeated measures, followed by Dunn's multiple comparison test, was used for comparison of the 

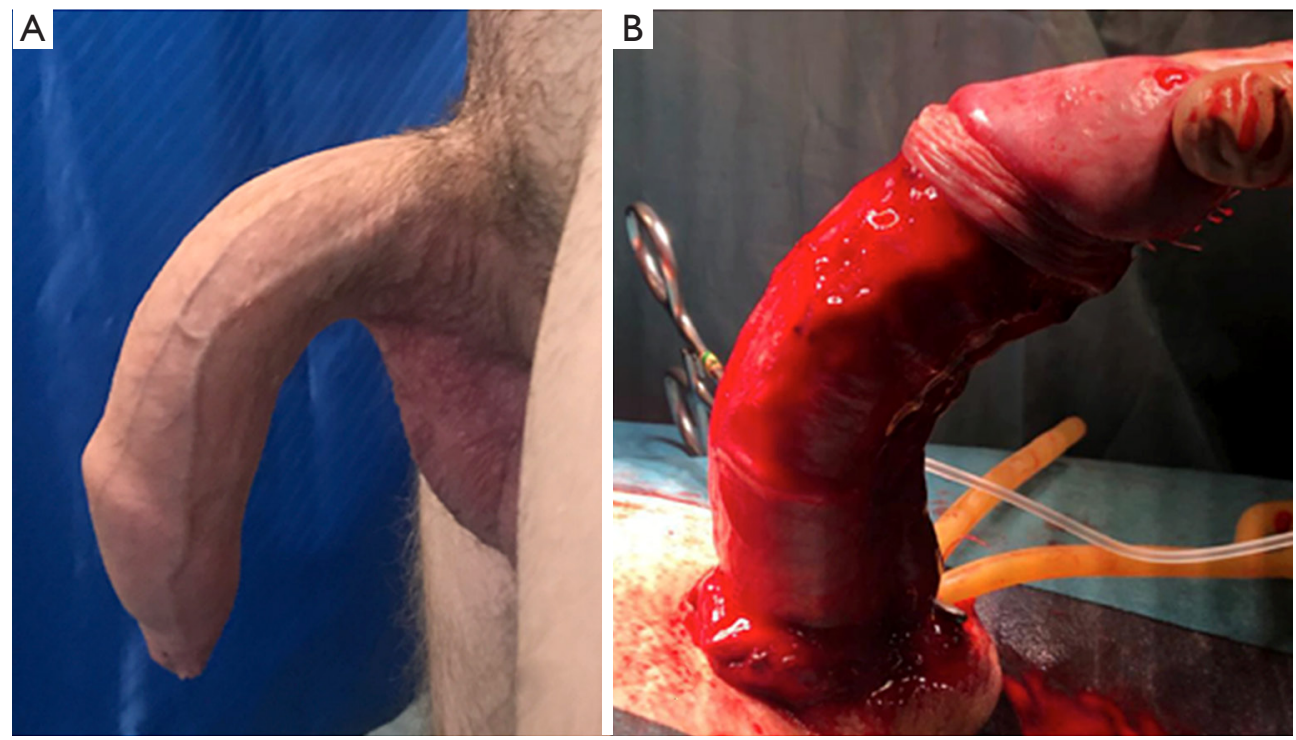

Figure 1 Assessment of penile curvatures. (A) Ventral penile curvature and phimosis. (B) Circumcision and penile degloving, artificial erection induction to confirm the curvature.

IIEF-5 among the three different time points (baseline, 6 and 12 months post-operation). A Pearson $r$ correlation coefficient was used for continuous variables for pre- and post-operation data. A multivariate logistic regression analysis (stepwise method) was performed to identify factors that might be independently associated with the presence of ED or with abnormal PSV. In these last analyses, only variables with $\mathrm{P}$ value $<0.05$ in the univariate analysis were used.

Statistical analyses were made using GraphPad Prism (version 5.0, La Jolla, CA, USA) and SPSS Software (PASW Version 21.0, SPSS Inc., Chicago, IL, USA). P values $<0.05$ were considered as statistically significant.

\section{Results}

\section{Baseline}

Sixty-four patients with PC were included in the study. The median age of the entire cohort of patients was 58.5 [17-71] years old. Eleven (17.2\%) of patients had CPC, whereas $53(82.8 \%)$ had PD. Mean angle of PC was not different between $\mathrm{CPC}$ and $\mathrm{PD}$ patients $\left(50^{\circ} \pm 14.5^{\circ}\right.$ vs. $51.1 \pm 16.5^{\circ}$, respectively; $\mathrm{P}=0.84)$. The clinical characteristics of patients at baseline are shown in Table 1 .

At baseline, 48 (75\%) patients had ED, whereas 16 (25\%) patients did not report ED at IIEF-5 (Table 2). Only two cases $(3.1 \%)$, with a PC angle of $40^{\circ}$ and $80^{\circ}$ reported severe ED at IIEF-5 and were included in the group of moderate ED in the further analyses. Mean PSV was $28.5 \pm 6.1 \mathrm{~cm} / \mathrm{s}$ and $19(29.7 \%)$ patients reported abnormal value (Table 2). IIEF-5 score and PSV positively correlate $(\mathrm{r}=0.559, \mathrm{P}<0.001$; Figure 7). Most cases with moderate or severe ED (57.1\%) had abnormal PSV, and none one of them has normal PSV $\left(\chi^{2}=24.54, \mathrm{P}<0.001\right.$; Figure 7$)$.

\section{Factors associated to ED}

Patients older than 60 years old had a significantly higher risk of $\mathrm{ED}$ compared to younger patients $(\mathrm{OR}=2.67$, 95\% CI: $\left.0.92-7.68, \chi^{2}=4.80, \mathrm{P}=0.03\right)$. Moreover, age was also significantly associated with $\operatorname{PSV}\left(\chi^{2}=6,24, \mathrm{P}=0.04\right)$. In particular, $44.4 \%$ of patients older than 60 years had abnormal PSV compared to those younger than 60 years old. $61.8 \%$ and $24.3 \%$ of younger patients had PSV in a grey zone or normal PSV, respectively. Patients with CPC had a significantly lower risk of ED compared to those with PD (OR $=0.19,95 \%$ CI: 0.06-0.57, $\chi^{2}=10.57$, $\mathrm{P}=0.01$ ). Evaluating the severity of $\mathrm{ED}$, we observed that $63.6 \%$ and $36.4 \%$ of patients with CPC had no-ED or mild ED, respectively, $v s .17 \%$ and $32.1 \%$ of those with PD $(\mathrm{P}=0.004$; Figure $8 A)$. None of those with CPC reported mild to severe ED. Furthermore, none of the patients CPC had abnormal PSV compared to $35.8 \%$ of those with PD $(\mathrm{P}<0.001$; Figure 8B). 
A
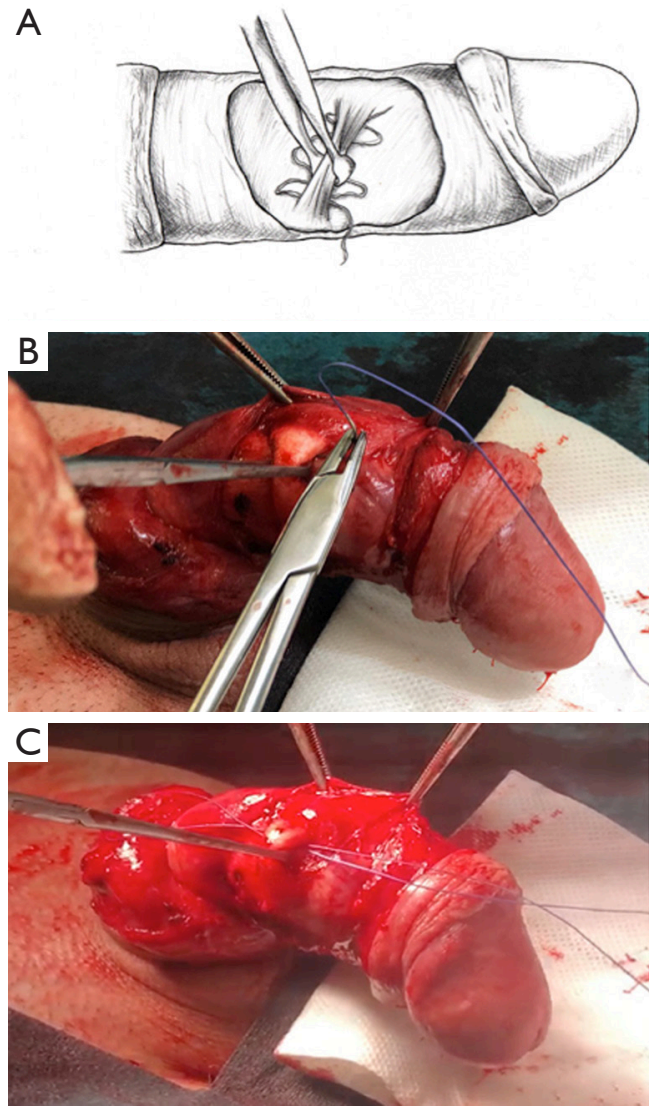

Figure 2 Tunica albuginea plication. (A) Second step of Nesbit modified corporoplasty without use of tourniquet. (B) Neurovascular bundles dissection and tunica albuginea plication with allis forceps. (C) Horizontal mattress continuous suture under allis forceps.

Patients with a PC angle $\geq 60^{\circ}$ had a significantly higher risk of $\mathrm{ED}$ in comparison to those with an angle $<60^{\circ}$ (OR $=2.67,95 \%$ CI: $\left.0.92-7.68, \chi^{2}=4.80, P=0.03\right)$. The angle of PC was also significantly associated with $\operatorname{PSV}\left(\chi^{2}=11.0\right.$, $\mathrm{P}=0.004)$. In particular, $51.9 \%$ and $37 \%$ of patients with an angle $\geq 60^{\circ}$ had abnormal PSV or PSV in the grey zone, respectively, compared to $13.5 \%$ and $64.9 \%$ of those having an angle $<60^{\circ}$. No differences were observed among patients with different direction of curvature and $\mathrm{ED}(\mathrm{P}=0.29)$ or PSV $(\mathrm{P}=0.31)$.

Patients with plaques had a significantly increased risk of ED compared to those without $(\mathrm{OR}=3.78,95 \%$ CI: 1.34 $\left.10.65, \chi^{2}=13.35, \mathrm{P}<0.001\right)$. When we evaluated the severity of $\mathrm{ED}$, we observed that $24.3 \%$ and $32.4 \%$ of patients with plaques vs. $14.8 \%$ and $7.4 \%$ of those without had mild-tomoderate or moderate-or-severe $\mathrm{ED}\left(\chi^{2}=15.32, \mathrm{P}=0.002\right.$;
Figure $8 C$ ). Moreover, the presence of plaques significantly correlated with PSV $\left(\chi^{2}=25.75, \mathrm{P}<0.001\right)$. In particular, one (3.7\%) patient without plaque reported abnormal PSV vs. $48.9 \%$ of those without. In contrast, none of the patients with plaques presented normal PSV compared to $40.7 \%$ of those without plaques (Figure $8 D$ ). The number of plaques (single $v$ s. multiple), as well as the size of the plaques $(<1 v s$. $\geq 1 \mathrm{~cm})$, were not associated with the presence of $\mathrm{ED}(\mathrm{P}=0.21$ and $\mathrm{P}=0.38$, respectively) or $\mathrm{PSV}(\mathrm{P}=0.90$ and $\mathrm{P}=0.62$, respectively).

Patients with pain showed a trend to a higher risk of ED compared to those without, although it was not statistically significant $\left(\mathrm{OR}=3.67,95 \% \mathrm{CI}: 0.51-26.22, \chi^{2}=2.19\right.$, $\mathrm{P}=0.14)$. On the other side, pain significantly correlated with PSV $\left(\chi^{2}=14.95, P=0.001\right)$. Particularly, none of the patients with pain had normal PSV compared to $21.2 \%$ of those without, whereas $75 \%$ vs. $19.2 \%$, respectively, had abnormal PSV. Patients presenting difficulty in penetration had a significantly increased risk to have ED compared to those without $\left(\mathrm{OR}=2.2,95 \% \mathrm{CI}: 1.04-4.66, \chi^{2}=6.99\right.$, $\mathrm{P}=0.008)$. Opposite to that, difficulty in penetration was not associated with PSV $(\mathrm{P}=0.23)$.

The presence of other risk factors, including trauma, hypospadias, Dupuytren syndrome and urethral chordee was not associated with ED $(\mathrm{P}=0.86)$ or PSV $(\mathrm{P}=0.34)$. No correlation was observed between the time from the onset of $\mathrm{PC}$ to surgery and $\mathrm{ED}(\mathrm{r}=0.168, \mathrm{P}=0.18)$ and $\mathrm{PSV}(\mathrm{r}=0.22$, $\mathrm{P}=0.08)$.

At the logistic regression, analysis including all variables that were significantly associated with the presence of ED at univariate analysis, only PD, presence of plaques and difficulty in penetration significantly correlated with ED (Table 3, Model 1). These same parameters continued to be significantly associated with ED also in the final multivariate model (Table 3, Model 2). Considering the presence of abnormal PSV, the logistic regression analysis including age, congenital curvature, angle, plaques and pain, showed that only the PD continues to be significantly associated with abnormal PSV (OR =9.38, 95\% CI: 1.02-86.21, $\mathrm{P}=0.048)$.

\section{Surgical procedure and clinical outcome}

No intraoperative bleeding was noted, and during the short-term follow-up no complications like hematomas or neurovascular bundle lesions were reported. The patients had no post-operative infections and no sensory change. At 6 months, no palpable subcutaneous indurations and no painful erections were detected. Post-operative 
A
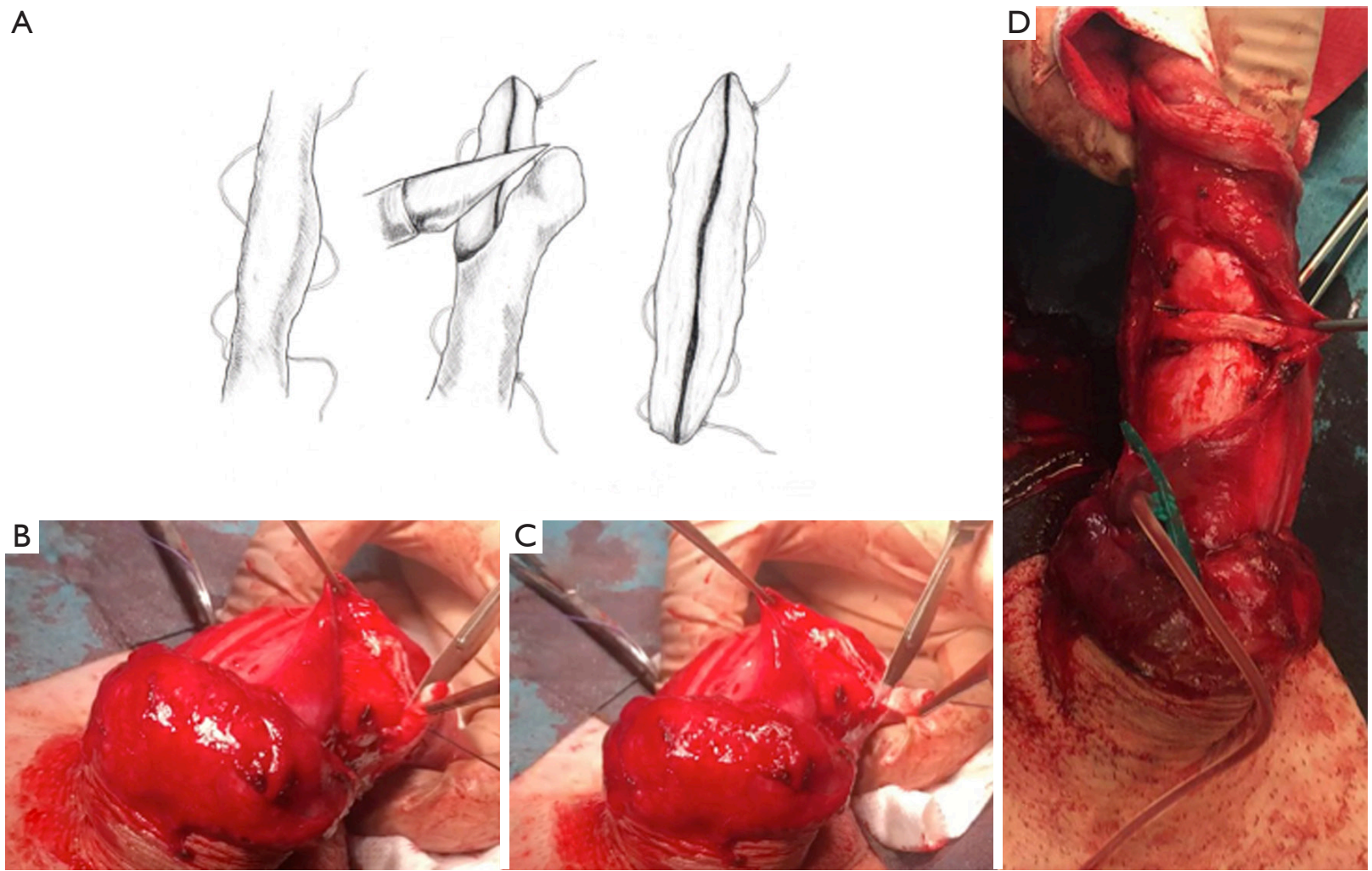

Figure 3 Albugineal tissue removal. (A) Third step of Nesbit modified corporoplasty. (B) Albugineal tunica incision with scalpel. (C) Albugineal excess tissue removal. (D) Absence of bleeding without tourniquet.

A

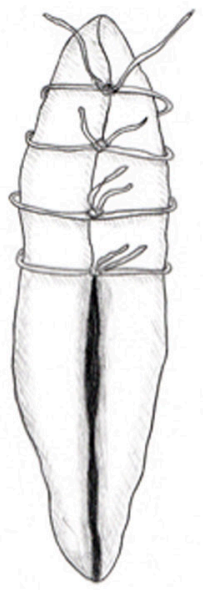

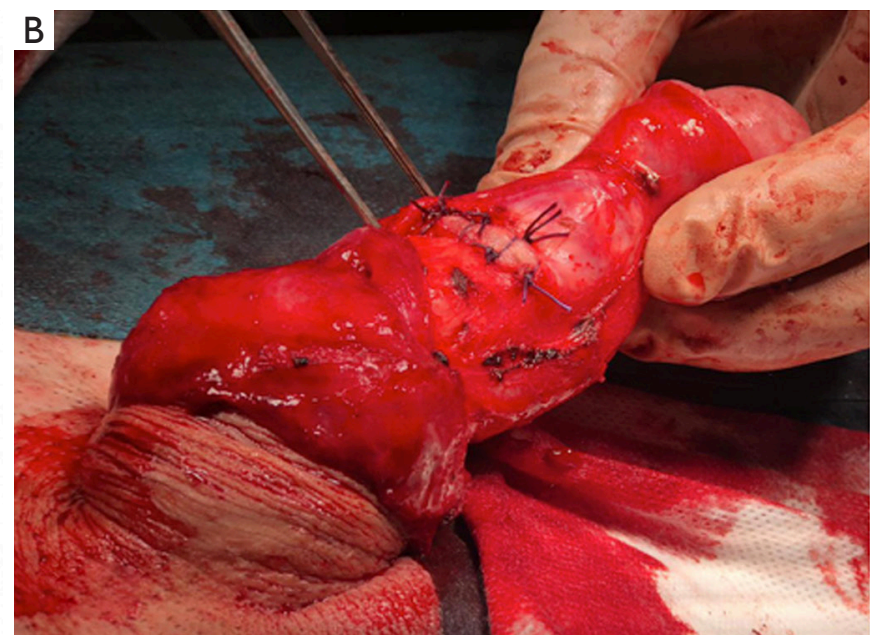

Figure 4 Suture of the albugineal breach. (A) Albugineal tunica breach ensuring. (B) Over and over interrupted absorbable suture. 

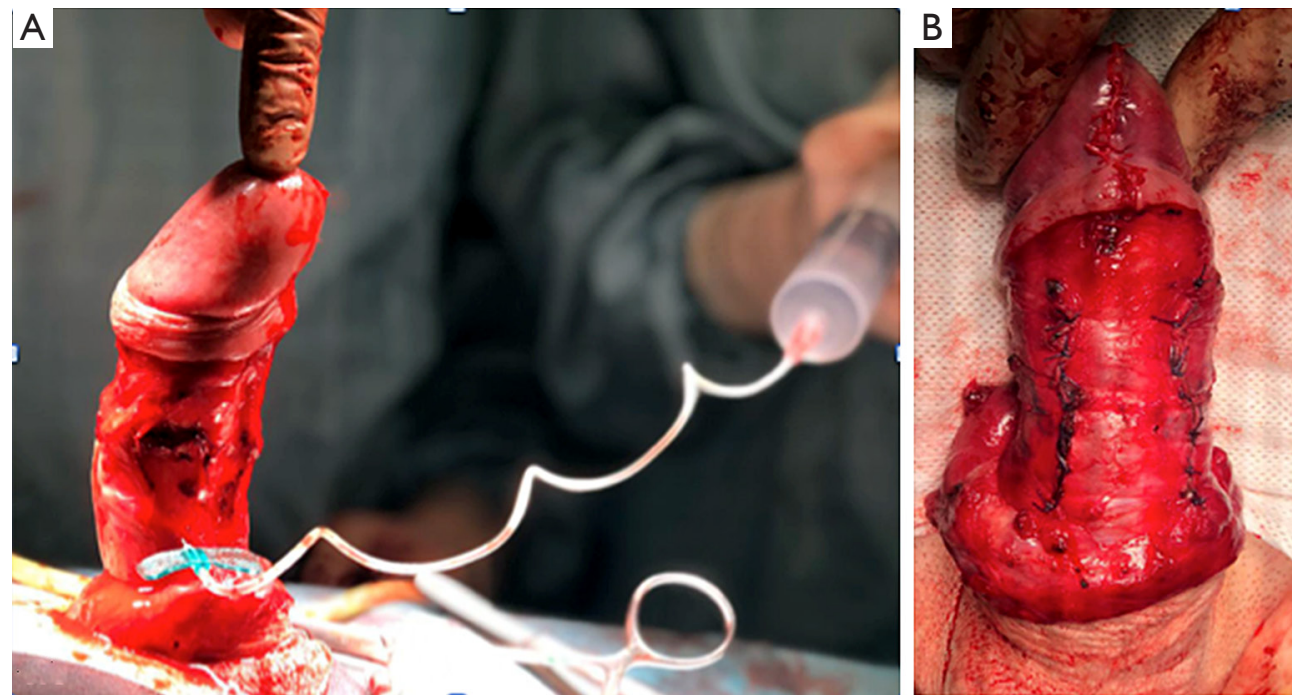

Figure 5 Assessment of penile correction. (A) Artificial erection induction to check curvature correction. (B) Buck's fascia periurethral interrupted absorbable suture.
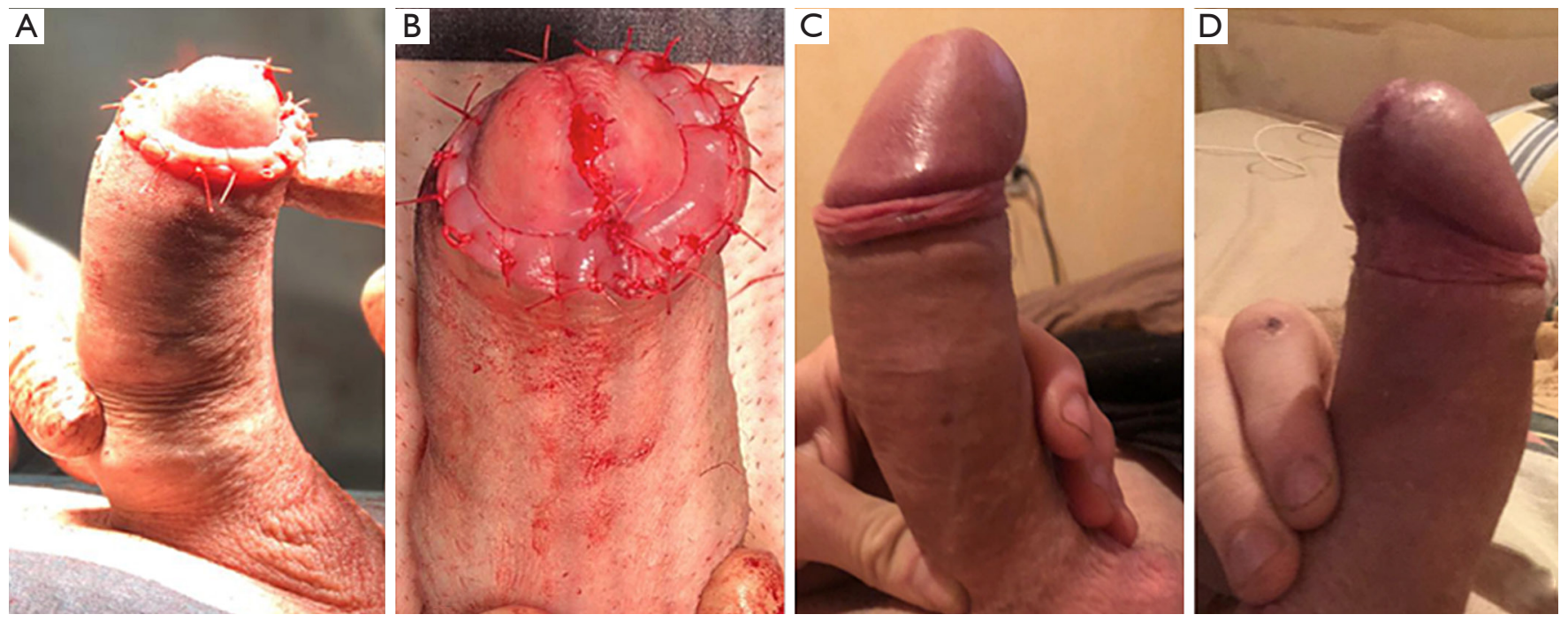

Figure 6 Penile skin closure. (A) Corpora cavernosum closure. (B) Penile skin coronal suture. (C) One-month follow-up with complete curvature resolution. (D) Excellent cosmetics results.

shortening was encountered in 38 (59.4\%) patients (mean $0.83 \pm 0.79 \mathrm{~cm}$ ) but it did not influence the high overall satisfaction rate of $91.4 \%$. Penile shortening was not associated with severity of $\mathrm{ED}\left(\chi^{2}=0.15, \mathrm{P}=0.92\right)$ and PSV $\left(\chi^{2}=2.32, \mathrm{P}=0.31\right)$ at 12 months, as well as did not correlated with none of the evaluated parameter at baseline, including angle and direction of $\mathrm{PC}(\mathrm{P}=0.31$ and $\mathrm{P}=0.93$, respectively). Particularly, patients with an angle $\geq 60^{\circ}$ had a slighter higher risk of penile shortening (OR $=1.37$, 95\% CI: $0.73-$
2.56) compared to those with an angle $<60^{\circ}$. After a followup of 12 months, only $2(3.1 \%)$ patients reported a slightly partial recurrence of curvature $(<15 \%)$ and continued to show mild and mild-to-moderate ED at IIEF-5 without request additional treatment. However, these patients had a primary angle of $\mathrm{PC}$ of $70^{\circ}$ and $80^{\circ}$, respectively, with mildto-moderate and severe ED at IIEF-5 at baseline. No longterm complications were found to request the redo surgery.

After both 6 and 12 months of follow-up, a significant 
Table 1 Characteristics of the patients at baseline (preoperative)

\begin{tabular}{|c|c|}
\hline Characteristics & Outcome \\
\hline Patients & 64 \\
\hline Age (years) & $58.5[17-71]$ \\
\hline Penile curvature (degrees) & $50^{\circ}\left[30^{\circ}-90^{\circ}\right]$ \\
\hline \multicolumn{2}{|l|}{ Angle of penile curvature } \\
\hline$<60^{\circ}$ & $37(57.8 \%)$ \\
\hline$\geq 60^{\circ}$ & 27 (42.2\%) \\
\hline \multicolumn{2}{|l|}{ Direction of curvature } \\
\hline Dorsal & $17(26.6 \%)$ \\
\hline Lateral left & $20(31.3 \%)$ \\
\hline Lateral right & $11(17.2 \%)$ \\
\hline Ventral & $16(25.0 \%)$ \\
\hline Congenital penile curvature & $11(17.2 \%)$ \\
\hline \multicolumn{2}{|l|}{ Number of plaques } \\
\hline None & $27(42.2 \%)$ \\
\hline Single & $25(39.1 \%)$ \\
\hline Multiple & $12(18.8 \%)$ \\
\hline \multicolumn{2}{|l|}{ Size of plaques (cm) } \\
\hline$<1 \mathrm{~cm}$ & $30(81.1 \%)$ \\
\hline$\geq 1 \mathrm{~cm}$ & $7(18.9 \%)$ \\
\hline \multicolumn{2}{|l|}{ Risk factors } \\
\hline Yes & $13(20.3 \%)$ \\
\hline No & $51(79.7 \%)$ \\
\hline \multicolumn{2}{|l|}{ Pain } \\
\hline Yes & $12(18.8 \%)$ \\
\hline No & $52(81.3 \%)$ \\
\hline \multicolumn{2}{|l|}{ Difficulty in penetration } \\
\hline Yes & $38(59.4 \%)$ \\
\hline No & $26(40.6 \%)$ \\
\hline $\begin{array}{l}\text { Time between the onset of penile } \\
\text { curvature and surgery (years) }\end{array}$ & 3 [2-15] \\
\hline
\end{tabular}

Values are reported as median [range] or number (\%).

improvement of ED was observed. Particularly, the mean IIEF-5 score increased from $17.1 \pm 5.2$ to $20.8 \pm 3.9$ at 6 months and to $21.8 \pm 3.4$ at 12 months $(\mathrm{P}<0.001$ in both cases). No case of moderate or severe ED was observed at the end of follow-up, where the majority of cases $(64.1 \%)$ did not report ED (Table 2). Mean PSV also significantly increased at the end of follow-up $(28.5 \pm 6.1$ at baseline $v$ s. $31.0 \pm 7.1$ at 12 months, $\mathrm{P}=0.03)$. However, no significant differences were observed evaluating the severity of PSV between the baseline and the end of follow-up (Table 2). In addition, after 12 months, IIEF-5 score and PSV positively correlated $(r=0.732, \mathrm{P}<0.001$; Figure $7 C)$ and all patients without ED had normal PSV or, in a large proportion $(58.5 \%), \mathrm{PSV}$ into grey zone $\left(\chi^{2}=34.55, \mathrm{P}<0.001\right.$; Figure $7 D) .92 \%$ of patients with abnormal PSV continued to have mild-to-moderate or mild ED.

\section{Discussion}

Surgeons proposed different shortening procedures for the correction of congenital and acquired PC. Generally, authors divide these procedures into two groups: plication corporoplasty and Nesbit corporoplasty (28). Plication corporoplasty, in contrast to Nesbit's corporoplasty, avoids the incision of tunica albuginea is a less invasive way with less post-operative complications such as bleeding, hematoma and erectile dysfunction (29). However, disadvantages of this technique exist and include: a higher percentage of relapses and recurrence, usually as a result of the insufficient tensile strength of the plications $(30,31)$, palpable subcutaneous knots or granuloma formation because of the use of nonabsorbable suture, which may cause pain and discomfort during erection $(30,32,33)$. In Nesbit corporoplasty, the incision of tunica albuginea ensures a permanent fusion of the tunical margins with long-term better results in terms of recurrence (34). However, the use of a tourniquet for a long time may be harmful to the sensory nerves and the erectile tissue (28). Currently, only a few studies demonstrated the damage of penile nerves and erectile tissues caused by long use of the tourniquet during tunical reconstruction with subsequent hypoxia. Bozkurt and colleagues investigated the effect of tourniquet application on rabbit corpus cavernosum penis. The results of their study suggest that the application time of up to $20 \mathrm{~min}$ is more appropriate instead of prolonged usage avoiding the alteration of endothelium-dependent muscarinic receptor-mediated relaxation responses (14). It has been shown that prolonged penile tourniquet application in rats may alter growth factors in penile tissue and may reduce the success rate of repair (16).

In this study, we presented our experience with the Nesbit modified corporoplasty presented from Rolle's group, in 2005, avoided the use of tourniquet during tunica 
Table 2 Logistic regression analysis for erectile disfunction evaluated by IIEF-5

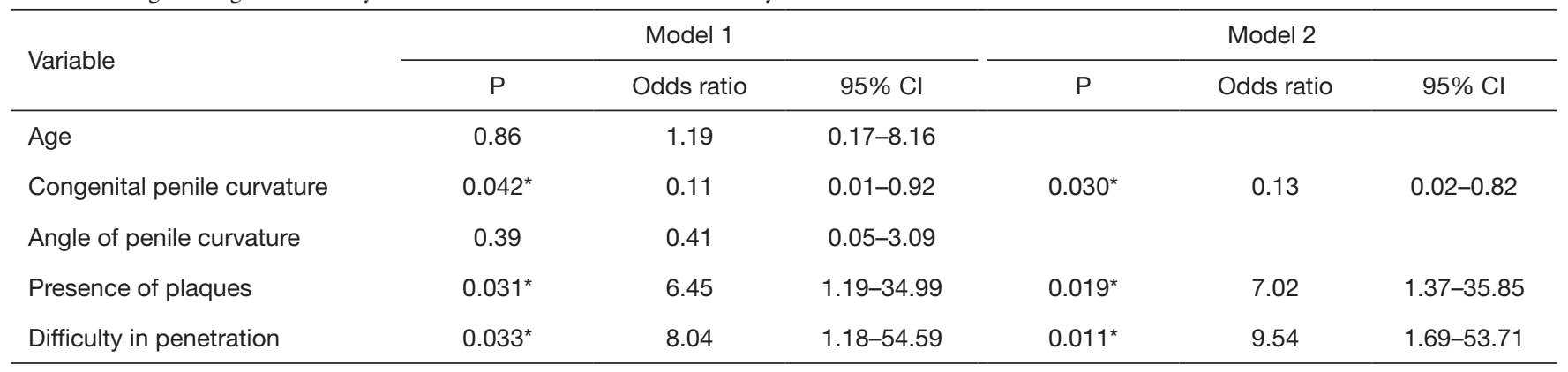

Model 2 is the final model evaluating only those variables that were statistically significant at the first analysis (model 1). A P value with * represents a $P$ statistically significant.

Baseline

A

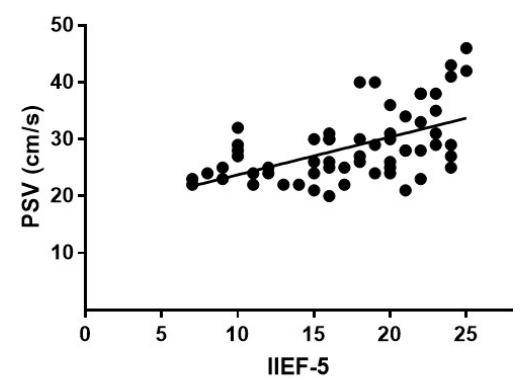

B

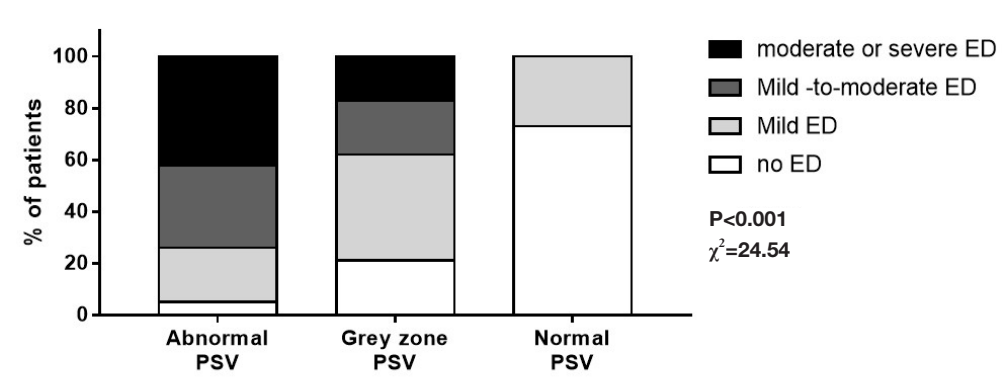

Follow-up at 12 months

C

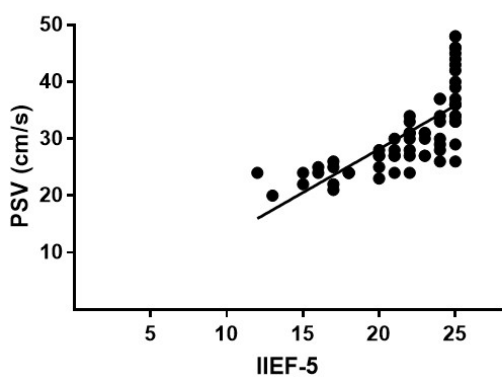

$r=0.559$

$P<0.001$

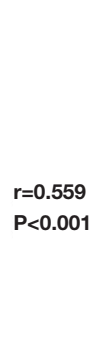

D

$r=0.732$
$P<0.001$

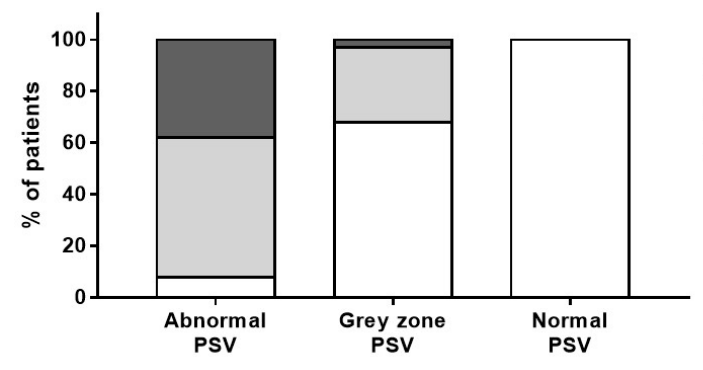

$\square$ Mild-to-moderate ED

$\square$ Mild ED

$\square$ no ED

$\mathbf{P}<0.001$

$\chi^{2}=34.55$

Figure 7 Correlation between erectile disfunction assessed by IIEF-5 and peak systolic velocity (PSV) score pre- and post-operative. IIF-5 and PSV positively correlate both at baseline (A) and after a follow-up of 12 months (C). (B) At baseline, 72.7\% and 27.3\% of patients with normal PSV had no- or mild-ED, respectively, compared to $20.6 \%$ and $41.2 \%$ of patients with PSV into grey zone and $5.3 \%$ and $21.1 \%$ of those with abnormal PSV. Most cases with moderate or severe ED (57.1\%) had abnormal PSV. (D) At follow-up after 12 months, all patients with normal PSV did not reported ED. Moreover, a large proportion (58.5\%) of cases without ED had a PSV into grey zone, while 2.4\% (vs. 6.3\% preoperative) continue to have abnormal PSV. The majority of patients with abnormal PSV had mild ED (53,8\%) or mild-tomoderate $\mathrm{ED}(38.5 \%$ ) vs. $26.8 \%$ and $2.9 \%$, respectively, of those having PSV into grey zone. Statistical analyses were performed by Pearson r correlation coefficient (A and C) and chi-square $\left(\chi^{2}\right)$ test (B and D). 
Congenital Penile Curvature or Peyronie's Disease
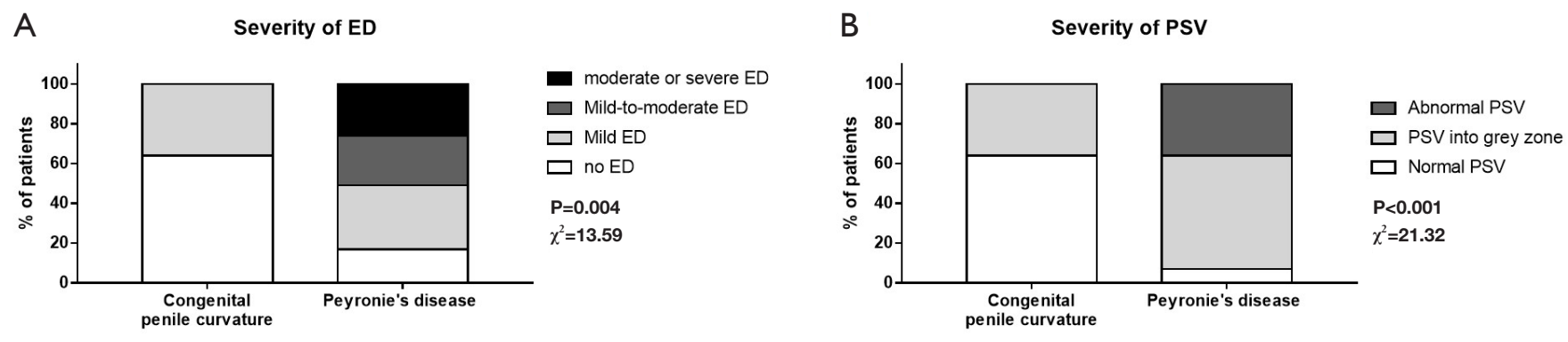

Presence of Plaques
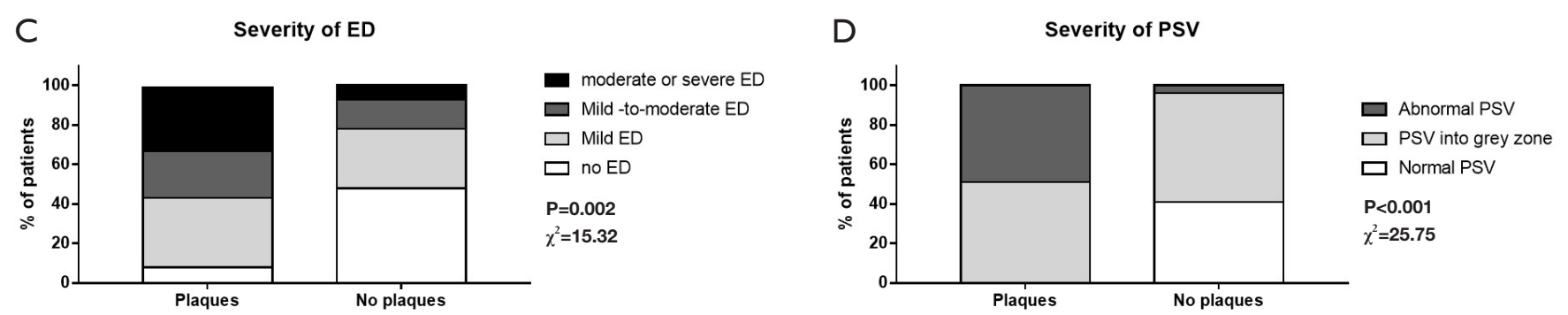

Figure 8 Association between cause of penile curvature and presence of plaques with severity of erectile disfunction and peak systolic velocity (PSV). (A) None of the patients with congenital penile curvature (CPC) had abnormal PSV compared to $35.8 \%$ of those with Peyronie's disease (PD). (B) Patients with CPC showed a normal or grey zone PSV (63.6\% and 36.4\%, respectively) vs. $7.5 \%$ and $56.6 \%$ of those without. (C) $24.3 \%$ and $32.4 \%$ of patients with plaques $v s .14 .8 \%$ and $7.4 \%$ of those without had mild-to-moderate or moderate-orsevere ED. (D) Only one (3.7\%) patients without plaque reported abnormal PSV vs. $48.9 \%$ of those without, whereas none of patients with plaques presented normal PSV compared to $40.7 \%$ of those without plaques. Statistical analyses were performed by chi-square $\left(\chi^{2}\right)$ test.

albuginea reconstruction, with some minimal technical differences (24). More specifically, in this study, the authors strictly limited the indications of Nesbit modified corporoplasty to patients with angle curvature between $30^{\circ}$ and $60^{\circ}$ and considered patients with curvatures greater than $60^{\circ}$ as better candidates for penile lengthening procedures (24). In contrast to this, we included in our study patients with $\mathrm{PC}$ angle from $30^{\circ}$ to $90^{\circ}$. Moreover, differently to Rolle's study, we included patients with CPC and PD and not only those with PD. The only technical difference between the technique used by from Rolle's group and our surgical procedure is that they applied a one 2-zero polyglycolic U-shaped knot on each side of the Allis clamp, whereas in our procedure we use a horizontal mattress continuous suture using a 2-0 absorbable polyglactin 910 like a "hinge" to minimize the intraoperative bleeding. The use of absorbable sutures minimizes, until deleting, the incidence of bothersome palpable knots at 12 months follow-up. Post-operative results were similar in terms of recurrent curvature but different for the post-operative shortening $(59.4 \%$ compare to $78 \%$ showed by Rolle et al. (24). After a follow-up of 12 months, only two patients $(3.1 \%)$ reported a recurrence of curvature $<15 \%$, but it is important to mention that these patients exhibited a severe curvature before surgery. Post-operative penile shortening is the most frequent complication of every plication and Nesbit procedures. In our study, the mean length loss was of $0.83 \pm 0.79 \mathrm{~cm}$, in accordance to what was previously reported (35). Different to a previous study (36), penile shortening was not significantly associated to direction and degree of curvature. In fact, we observed only a trend of increased risk of penile shortening in those patients who had an angle $\geq 60^{\circ}$. However, penile shortening did not influence the erectile function after 1 year of follow-up.

The main outcome of the present study was the erectile function evaluated by the IIEF-5. By using the modified Nesbit procedure, we demonstrated that the mean IIEF5 score increased from $17.1 \pm 5.2$ to $20.8 \pm 3.9$ at 6 months 
Table 3 Evaluation of the ED severity through IIEF-5 and PSV at baseline and during the follow-up

\begin{tabular}{|c|c|c|c|c|c|c|c|c|c|}
\hline Variable & $\begin{array}{c}\text { Baseline } \\
\text { Value }\end{array}$ & \multicolumn{3}{|c|}{6 months postoperative } & \multicolumn{5}{|c|}{12 months postoperative } \\
\hline IIEF-5 & $17.1 \pm 5.2$ & $20.8 \pm 3.9$ & $<0.0001$ & - & $21.8 \pm 3.4$ & $<0.0001$ & - & 0.02 & - \\
\hline Severity of ED & & & $<0.001$ & 40.6 & & $<0.001$ & 41.2 & $<0.001$ & 67.6 \\
\hline No ED & $16(25 \%)$ & $32(50 \%)$ & & & $41(64.1 \%)$ & & & & \\
\hline Mild-to-moderate ED & $13(20.3 \%)$ & $9(14.1 \%)$ & & & $6(9.4 \%)$ & & & & \\
\hline Moderate or severe ED & $14(21.9 \%)$ & $1(1.6 \%)$ & & & 0 & & & & \\
\hline $\mathrm{PSV}(\mathrm{cm} / \mathrm{s})$ & $28.5 \pm 6.1$ & NA & - & - & $31.0 \pm 7.1$ & 0.03 & - & - & - \\
\hline Severity of PSV & & NA & - & - & & 0.36 & 2.06 & - & - \\
\hline Abnormal & $19(29.7 \%)$ & & & & $13(20.3 \%)$ & & & & \\
\hline
\end{tabular}

Values are reported as mean \pm SD or number (\%). Statistical analyses between baseline and 6 months postoperative $\left({ }^{*}\right)$, between baseline and 12 months postoperative $\left(^{\star *}\right)$ and between 6 and 12 months postoperative $\left.{ }^{(* \star}\right)$ were performed by Mann-Whitney test or ANOVA with multiple comparison and Chi-square $\left(\chi^{2}\right)$ test for continuous or dichotomic variables, respectively. ED, erectile disfunction; NA, parameter not available; PSV, peak systolic velocity; -, not applicable.

and to $21.8 \pm 3.4$ at 12 months, showing a significant improvement in erectile function. The outcome achieved in our study was similar to those reported in other studies using different techniques (37), but it was higher the those reported by Rolle et al., which showed a mean value of IIEF-5 of $17.83 \pm 4.17$ at baseline vs. $19 \pm 4.63$ at 6 months follow-up. This discrepancy could be explained by the different inclusion criteria and the different time of follow-up between these two studies. On the other hand, satisfaction rate in our patients was slightly lower compared to the data described by Rolle (91.4\% vs. 94\%), probably because we treated also curvatures $>60^{\circ}$. Moreover, in some studies erectile function raised up after surgery without reaching statistical significance, probably for the use of tourniquet during the technique and the prolonged time of penile ischemia $(34,35)$. Rolle and colleagues did not consider the advantages of the penile clampless, probably because there was no scientific demonstration of the penile damage after a long period of ischemia at the time of the study (14). Moreover, we also demonstrated that PSV significantly increased at the end of follow-up $(28.5 \pm 6.1$ at baseline $v s .31 .0 \pm 7.1$ at 12 months) and significantly correlated with the erectile function both at baseline and at follow-up. Particularly, at the end of follow-up, all patients with normal PSV did not showed ED, whereas $27.3 \%$ of these patients showed mild ED at the beginning of the study. In this study, we were also able to demonstrate the clinical parameters that were significantly associated with the presence of ED pre-operatively. In fact, the included patients were well characterized before undergoing such surgical procedures. Considering all the evaluated parameters, age $>60$ years old, the presence of a $\mathrm{PD}$ ( $v s$. CPC), a PC angle $\geq 60^{\circ}$, the presence of plaques and the difficulty in penetration were significantly associated with a higher risk of ED at univariate analyses. However, at multivariate analysis, only $\mathrm{PD}$, the presence of plaques and the difficulty in penetration were confirmed to be significantly independent factors of ED.

The goal of our study was to take advantages of the Nesbit techniques, avoiding disadvantages of the plication. The modified Nesbit procedure let us to: avoid bleeding during opening of cavernous cavity; reduce erectile tissue damage during incision and excision of the tunica albuginea; use of absorbable suture in order to avoid palpable subcutaneous knots or granuloma formation; perform a tunical repair on penis in its flaccid state avoiding the use of tourniquet during tunical reconstruction and reduce recurrence rate of the plication technique. After the operation most authors use antiandrogens to decrease albugineal tension during erection in order to reduce 
the possibility of suture failed, suggesting also 2 months of abstinence from sexual intercourse (38-40). In our experience, we do not use antiandrogens and we suggest just 1 month of abstinence from sexual intercourse. Despite the encouraging results of this study, there are some limitations due to the retrospective nature of the study and the small number of patients included in our study. However, we demonstrated the advantages of the modified Nesbit technique both in patients with CPC and PD, as well as in patients with angle curvature $>60^{\circ}$, which are usually more difficult to treat. Moreover, we also showed clinical factors that are independently associated with ED. This could have clinical implications such as suggesting patients who could benefit the most from such surgical procedures. Prospective studies including a larger number of patients are needed to confirm our results.

\section{Conclusions}

From the results obtained, considering the post-operative erectile function and no recurrence of curvature, we were able to validate the surgical technique of Rolle's team in a larger number of patients. We demonstrated that Nesbit modified corporoplasty without tourniquet application during reconstruction is a safe and effective surgical procedure for all kind of shortening corporoplasty and we suggest introducing it into surgical practice to reduce the time of penile ischemia.

\section{Acknowledgments}

Thanks to Tereza Jandova for the English revision.

Funding: None.

\section{Footnote}

Reporting Checklist: The authors have completed the STROBE reporting checklist. Available at http://dx.doi. org/10.21037/tau-20-1338

Data Sharing Statement: Available at http://dx.doi. org/10.21037/tau-20-1338

Peer Review File: Available at http://dx.doi.org/10.21037/ tau-20-1338

Conflicts of Interest: All authors have completed the ICMJE uniform disclosure form (available at http://dx.doi. org/10.21037/tau-20-1338). The authors have no conflicts of interest to declare.

Ethical Statement: The authors are accountable for all aspects of the work in ensuring that questions related to the accuracy or integrity of any part of the work are appropriately investigated and resolved. The study was conducted in accordance with the Declaration of Helsinki (revised in 2013) and was approved by the Ethics Committee for Biomedical Research of the provinces of Chieti and Pescara and the 'G. D'Annunzio' University of Chieti and Pescara (01/26-01-2017). A written informed consent was obtained from all patients.

Open Access Statement: This is an Open Access article distributed in accordance with the Creative Commons Attribution-NonCommercial-NoDerivs 4.0 International License (CC BY-NC-ND 4.0), which permits the noncommercial replication and distribution of the article with the strict proviso that no changes or edits are made and the original work is properly cited (including links to both the formal publication through the relevant DOI and the license). See: https://creativecommons.org/licenses/by-nc-nd/4.0/.

\section{References}

1. Montag S, Palmer LS. Abnormalities of penile curvature: chordee and penile torsion. Scientific World Journal 2011;11:1470-8.

2. Nehra A, Alterowitz R, Culkin DJ et al. Peyronie's Disease: AUA Guideline. J Urol 2015;194:745-53.

3. Brimley SC, Yafi FA, Greenberg J, et al. Review of Management Options for Active-Phase Peyronie's Disease. Sex Med Rev 2019;7:329-37.

4. Egydio PH, Sansalone S. Peyronie's reconstruction for maximum length and girth gain: geometrical principles. Adv Urol 2008;2008:205739.

5. Chung E, Ralph D, Kagioglu A, et al. Evidence-Based Management Guidelines on Peyronie's Disease. J Sex Med 2016;13:905-23.

6. Nesbit RM. Congenital curvature of the phallus: report of three cases with description of corrective operation. J Urol 1965;93:230-2.

7. Langston JP, Carson CC 3rd. Peyronie disease: plication or grafting. Urol Clin North Am 2011;38:207-16.

8. Sasso F, Vittori M, D'Addessi A, et al. Penile curvature: an update for management from 20 years experience in a high volume centre. Urologia 2016;83:130-8. 
9. Hatzimouratidis K, Eardley I, Giuliano F, et al. EAU guidelines on penile curvature. Eur Urol 2012;62:543-52.

10. Austoni E, Altieri VM, Tenaglia R. Trans-scrotal penile degloving, a new procedure for corporoplasties. Urologia 2012;79:200-10.

11. Schultheiss D, Meschi MR, Hagemann J, et al. Congenital and acquired penile deviation treated with the essed plication method. Eur Urol 2000;38:167-71.

12. Perovic SV, Djordjevic ML, Djakovic NG. A new approach to the treatment of penile curvature. J Urol 1998;160:1123-7.

13. Yachia D. Our experience with penile deformations: incidence, operative techniques, and results. J Androl 1994;15 Suppl:63S-68S.

14. Bozkurt NB, Moralioglu S, Vural IM, et al. Does tourniquet application alter the nitrergic responses of rabbit corpus cavernosum penis? A functional study. World J Urol 2008;26:191-6.

15. Saenz de Tejada I, Kim NN, Goldstein I, et al. Regulation of pre-synaptic alpha adrenergic activity in the corpus cavernosum. Int J Impot Res 2000;12 Suppl 1:S20-5.

16. Kaya M, Soyer T, Ayva S, et al. Effect of penile tourniquet on growth factors in rat penile tissue. Eur J Pediatr Surg 2009;19:236-40.

17. Di Giulio C, Bianchi G, Cacchio M, et al. Carotid body HIF-1alpha, VEGF and NOS expression during aging and hypoxia. Adv Exp Med Biol 2003;536:603-10.

18. Verratti V, Ferrante C, Soranna D, et al. Effect of highaltitude trekking on blood pressure and on asymmetric dimethylarginine and isoprostane production: Results from a Mount Ararat expedition. J Clin Hypertens (Greenwich) 2020;22:1494-503.

19. Dean RC, Lue TF. Physiology of penile erection and pathophysiology of erectile dysfunction. Urol Clin North Am 2005;32:379-95, v.

20. Verratti V, Di Giulio C, Berardinelli F, et al. The role of hypoxia in erectile dysfunction mechanisms. Int J Impot Res 2007;19:496-500.

21. Verratti V, Falone S, Fanò G, et al. Effects of hypoxia on nocturnal erection quality: a case report from the Manaslu expedition. J Sex Med 2011;8:2386-90.

22. Keoghane SR, Sullivan ME, Miller MAW. The aetiology, pathogenesis and management of priapism. BJU Int 2002;90:149-54.

23. Burnett AL. Pathophysiology of priapism: dysregulatory erection physiology thesis. J Urol 2003;170:26-34.

24. Rolle L, Tamagnone A, Timpano M, et al. The Nesbit operation for penile curvature: an easy and effective technical modification. J Urol 2005;173:171-3; discussion 173-4.

25. Jung DC, Park SY, Lee JY. Penile Doppler ultrasonography revisited. Ultrasonography 2018;37:16-24.

26. Rosen RC, Cappelleri JC, Smith MD, et al. Development and evaluation of an abridged, 5-item version of the International Index of Erectile Function (IIEF-5) as a diagnostic tool for erectile dysfunction. Int J Impot Res 1999;11:319-26.

27. Likert R. A Technique for the Measurement of Attitudes. Arch Psychol 1932;140:1-55.

28. Perdzyński W, Adamek M. A new corporoplasty based on stratified structure of tunica albuginea for the treatment of congenital penile curvature - long-term results. Cent European J Urol 2015;68:102-8.

29. Hsieh JT, Liu SP, Chen Y, et al. Correction of congenital penile curvature using modified tunical plication with absorbable sutures: the long-term outcome and patient satisfaction. Eur Urol 2007;52:261-6.

30. Poulsen J, Kirkeby HJ. Treatment of penile curvature-A retrospective study of 175 patients operated with plication of the tunica albuginea or with the Nesbit procedure. Br J Urol 1995;75:370-4.

31. Schwarzer JU, Steinfatt H. Tunica albuginea underlap - a new modification of Nesbit Procedure: description of the technique and preliminary results. J Sex Med 2012;9:2970-4.

32. Baskin LS, Lue TF. The correction of congenital penile curvature in young men. Br J Urol 1998;81:895-9.

33. Salem EA. Modified 16-Dot plication technique for correction of penile curvature: prevention of knot-related complications. Int J Impot Res 2018;30:117-21.

34. Hamed HA, Roaiah M, Hassanin AM, et al. A new technique, combined plication-incision (CPI), for correction of penile curvature. Int Braz J Urol 2018;44:180-7.

35. Sokolakis I, Schönbauer P, Mykoniatis I, et al. Long-Term Results after Surgical Treatment of Congenital Penile Curvature Using a Modified Nesbit Technique. World J Mens Health 2020;38:564-72.

36. Greenfield JM, Lucas S, Levine LA. Factors affecting the loss of length associated with tunica albuginea plication for correction of penile curvature. J Urol 2006;175:238-41.

37. Vicini P, Di Nicola S, Antonini G, et al. Geometrical modified nesbit corporoplasty to correct different types of penile curvature: description of the surgical procedure based on geometrical principles and long-term results. Int 
J Impot Res 2016;28:209-15.

38. Yachia D. Modified corporoplasty for the treatment of penile curvature. J Urol 1990;143:80-2.

39. Gholami SS, Lue TF. Correction of penile curvature using the 16-dot plication technique: a review of 132 patients. $\mathrm{J}$

Cite this article as: Altieri VM, Greco F, Lisanti RC, Altieri B, Esperto F, Cindolo L, Castellucci R, Della Camera PA, Sangiorgi GM, Verratti V. Clinical and penile Doppler outcomes using a modified, tourniquet free, Nesbit plication for severe Peyronie's disease. Transl Androl Urol 2021;10(7):28572870. doi: $10.21037 /$ tau-20-1338
Urol 2002;167:2066-9.

40. Chen R, McCraw C, Lewis R. Plication proceduresexcisional and incisional corporoplasty and imbrication for Peyronie's disease. Transl Androl Urol 2016;5:318-33. 